\title{
Endoscopy after bariatric surgery
}

\author{
Chrysoula P. Malli, Athanasios D. Sioulas, Theodoros Emmanouil, George D. Dimitriadis, \\ Konstantinos Triantafyllou
}

Attikon University General Hospital, Medical School, National and Kapodistrian University, Athens, Greece

\section{Abstract}

\begin{abstract}
Obesity is a global epidemic with significant morbidity and mortality. Weight loss results in reduction of health risks and improvement in quality of life, thus representing a goal of paramount importance. Bariatric surgery is the most efficacious choice compared to conservative alternatives including diet, exercise, drugs and behavioral modification to treat obese patients. Following bariatric operations, patients may present with upper gastrointestinal tract complaints that warrant endoscopic evaluation and the various bariatric surgery types are often linked to complications. A subset of these complications necessitates endoscopic interventions for accurate diagnosis and effective, minimal invasive treatment. This review aims to highlight the role of upper gastrointestinal endoscopy in patients who have undergone bariatric surgery to evaluate and potentially treat surgery-related complications and upper gastrointestinal symptoms.
\end{abstract}

Keywords Obesity, bariatric surgery, endoscopy, complications, altered gastrointestinal anatomy

Ann Gastroenterol 2016; 29 (3): 1-9

\section{Introduction}

Obesity, defined as body mass index (BMI) greater than $30 \mathrm{~kg} / \mathrm{m}^{2}$, is a global epidemic. In 2013, there were more than 500 million obese individuals worldwide and estimations double their number within the next decades. Its prevalence is high in all age groups and it is associated with significant morbidity, mortality and healthcare costs [1].

Treatment options are suggested on an individualized pattern and include non-surgical methods such as diet, exercise, pharmacologic agents and behavioral modifications and surgical procedures. The latter are offered in carefully selected patients with severe obesity $\left(\right.$ BMI $>40 \mathrm{~kg} / \mathrm{m}^{2}$ ) or those with a BMI of $>35 \mathrm{~kg} / \mathrm{m}^{2}$ and serious comorbidities, after failure of the initial conservative measures. Bariatric surgical procedures include the most commonly performed

Hepatogastroenterology Unit, Second Department of Internal Medicine, Research Institute and Diabetes Center, Attikon University General Hospital, Medical School, National and Kapodistrian University, Athens, Greece

\section{Conflict of Interest: None}

Correspondence to: Konstantinos Triantafyllou, Ass. Professor of Gastroenterology, Hepatogastroenterology Unit, Second Department of Internal Medicine, Research Institute and Diabetes Center, Attikon University General Hospital, Rimini 1, 12462 Athens, Greece, Tel.: +30 210 5832090, Fax: +30 2105326422 ,

e-mail: ktriant@med.uoa.gr

Received 26 February 2016; accepted 08 April 2016; published online 19 April 2016

DOI: http://dx.doi.org/10.20524/aog.2016.0034 laparoscopic or open Roux-en-Y gastric by-pass (RYGB), sleeve gastrectomy (SG), vertical banded gastroplasty (VBG), laparoscopic adjustable gastric band (LAGB), biliopancreatic diversion with duodenal switch (BPD/DS) and laparoscopic mini gastric by-pass (MGB). All procedures are restrictive in nature except for RYGB and BPD/DS which exhibit additive malabsorptive effects [2-4].

The post-operative upper gastrointestinal (GI) track imposes certain difficulties for its examination to the endoscopist. Moreover, some of the early and late post-bariatric surgery symptoms and complications that may arise can be managed endoscopically. This review aims to highlight endoscopy technical issues in the operated stomach and the role of endoscopy for the diagnosis and therapeutic management of post-bariatric surgery symptomatic patients.

\section{Materials and methods}

We carried out a thorough literature review to identify all articles published in English from January 1985 to January 2016 regarding endoscopic management in post-bariatric surgery patients. The search was performed in the PubMed electronic database using the general term "endoscopy AND bariatric surgery". Thereafter, a manual search of the references cited in the key articles was performed. Each study was cross-checked by three authors (CPM, ADS, TE) to achieve the maximum completeness of the included reports. In case of disagreement with respect to the appropriateness of a potentially relevant article, the senior author (KT) made the final decision. From the initially retrieved 1243 articles only 71 original studies, 
case series and reports serve the purpose of the present review and are further discussed. Excluded were papers referring to surgical techniques, medical management of various postbariatric surgery complications as well as those evaluating endoscopy in the pre-operative setting. Additionally, data from meta-analyses, systematic reviews and reviews are mentioned, where suitable.

\section{Upper GI tract endoscopy after bariatric surgery}

It is essential for the gastroenterologist to understand the anatomic alterations of the upper GI tract, in order to recognize normal and abnormal findings and make appropriate diagnostic and therapeutic decisions. The expected endoscopic findings after a RYGB procedure include a normal esophagus and gastroesophageal junction along with a proximal gastric pouch of various sizes and the gastrojejunal (GJ) anastomosis. The latter is typically sized $10-12 \mathrm{~mm}$; however, stenosis, dilation and ulcers may also develop at this site.

Beyond GJ anastomosis, a blind, short limb is frequently visible. The length of the efferent Roux limb may exceed $150 \mathrm{~cm}$, thus needing a colonoscope (adult or pediatric) or enteroscope to be examined. Straight advancing, the jejunojejunal anastomosis can be reached and with suitable maneuvers entrance in the duodenum and identification of the major papilla may be accomplished [5].

The remaining common types of bariatric surgery pose significantly less difficulty than RYGB in terms of endoscopic evaluation. VBG procedure creates a gastric pouch separated with a banded stoma sized 10-12 $\mathrm{mm}$. The distal stomach and duodenum can be easily visualized, once the stoma is passed. LAGB operation produces a circumferential extrinsic compression in the proximal stomach recognizable during endoscopy. Careful inspection at this site may reveal band slippage or band erosion. Finally, SG results in a tubular stomach due to a staple line in parallel with the lesser curvature. Noteworthy, ulcerations and wall defects may appear along the staple line. These operations allow endoscopic retrograde cholangiopancreatography (ERCP) performance using a standard duodenoscope [6].

\section{Endoscopy for the management of symptoms and complications}

\section{Early complications}

\section{Anastomotic leak and fistula}

Gastric leaks after bariatric operations represent one of the most serious complications with widely variable reported rates. According to a recent review, the incidence of leaks after open and laparoscopic RYGB ranges from 1.7 to $2.6 \%$ and from 2.1 to $5.2 \%$, respectively. SG is complicated with leaks in up to $5.1 \%$ of cases [3]. Leaks usually present with tachycardia in
$72-92 \%$ of patients and they are associated with mortality rates ranging from 6 to $14.5 \%$, although rates as high as $40 \%$ have been reported $[3,7,8]$.

Accumulating evidence supports the use of both selfexpandable metallic (SEMS) and plastic stents (SEPS) along with conservative measures to treat post-surgery leaks. In 2006, Merrifield BF et al presented the endoscopic repair of gastric leaks in three patients after RYGB using Polyflex (Boston Scientific Corporation, Natick, MA, USA) esophageal stents. Durable fistula closure was achieved in all three patients, while one migrated stent had been retrieved endoscopically [9]. During the same year, Eubanks et al presented his experience using stents in 19 patients with staple line complications after bariatric surgery: 11 of them had acute leaks, 2 chronic fistula and 6 strictures. All patients were treated with endoscopic stent placement (11 SEMS, 23 SEPS). Treatment failure occurred in one patient in each group. Eventually, $58 \%$ of the stents migrated necessitating surgical removal in 3 of them [10]. Accordingly, partially-covered SEMS were introduced in 21 patients with large anastomotic leaks; 15 gastrocutaneous, two duodenocutaneous, three gastroperitoneal and one gastrobronchial fistulas, respectively. Overall success rate reached $81 \%$. Best results were achieved in the RYGB and BPD groups (100\%), while gastrocutaneous fistulas on a sleeve suture proved the most difficult to treat [11]. In another retrospective study, 18 patients (14 bariatrics) underwent endoscopic stent placement -successful in 13 of them-due to anastomotic complications; 13 anastomotic leaks, three strictures and two fistulas. Five patients required endoscopic or surgical intervention, while stent migration that occurred in four patients was managed endoscopically. There were two deaths unrelated to stent placement [12].

In a meta-analysis of 7 studies including 67 bariatric patients with evidence of anastomotic leaks, the proportion of successful leak closures using self-expandable stents was $87.8 \%$. Of note, $9 \%$ of patients required revision surgery, while stent migration was reported in $16.9 \%$ of them [13]. The authors proposed the optimal time for stent removal to be between 6 to 8 weeks since that time period seems to prevent both incomplete closure, as well as stent migration or mucosal hypertrophy leading to increased difficulty of stent extraction or dysphagia that may require endoscopic treatment. However, there are currently no specific evidence-based recommendations regarding criteria and timing of stent removal. Finally, Murad et al reported on the stent treatment of 47 patients with acute leaks after bariatric surgery. 41 of them were healed with stent treatment alone and 5 of 6 persisting leaks required laparoscopic intervention; complication rate was $28.7 \%$ and there was no mortality [14].

With specific regard to laparoscopic SG, a recent large retrospective series and systematic analyses report a postoperative leak rate ranging from 1.5 to $2.8 \%$. In terms of management, a combination of endoscopic stent placement and percutaneous drainage, antibiotics, as well as a short duration of parenteral nutrition usually provides very good results. Therefore, a re-operation is of no need in the vast majority of the cases [15-19].

As concluded from the aforementioned studies, leaks can be successfully and safely treated using endoscopic stents 
in the majority of cases. However, treatment failures as well as complications do occur, necessitating re-interventions. Gastrocutaneous fistulas are the most difficult to treat, thus necessitating surgical intervention. A major issue on leak treatment is stent migration that requires re-intervention and exposes patients to complication risks. The stents used in the presented studies vary from 16 to $22 \mathrm{~mm}$ in diameter and may reach up to $18 \mathrm{~cm}$ in length [9-14]. To prevent migration, larger stents (up to $25-28 \mathrm{~cm}$ ) may be required [20]. These stents are not specifically designed for the surgically altered upper GI anatomy, they are not widely available in the market and they require sufficient expertise to be successfully placed. Open to discussion remains the selection of stent type (e.g. metallic versus plastic), since there are not comparative studies in the literature. Theoretically, metallic stents (Fig. 1) are easier to be placed than the non-preloaded SEPS and with lower risk of migration, while plastic stents are easier and safer to remove. Undoubtedly, these assumptions require high-powered controlled studies to be confirmed or rejected.

Furthermore, either in combination with stent sealing or alone, endoscopically inserted nasocystic catheters, one or more double pig-tail stents as well as sponges connected transnasally to an external vacuum system have been used to drain leak-associated fluid collections. However, evidence in bariatrics is limited [21,22].

Beyond the above-mentioned endoscopic treatment methods for post-RYGB leaks, a couple of studies have highlighted the role of intra-operative endoscopy (IOE) to prevent such a complication [23,24]. Accordingly, IOE can readily detect anastomotic leaks thus indicating the need for subsequent operative maneuvers to reduce post-operative morbidity. Nevertheless, relevant randomized comparative studies are still lacking.

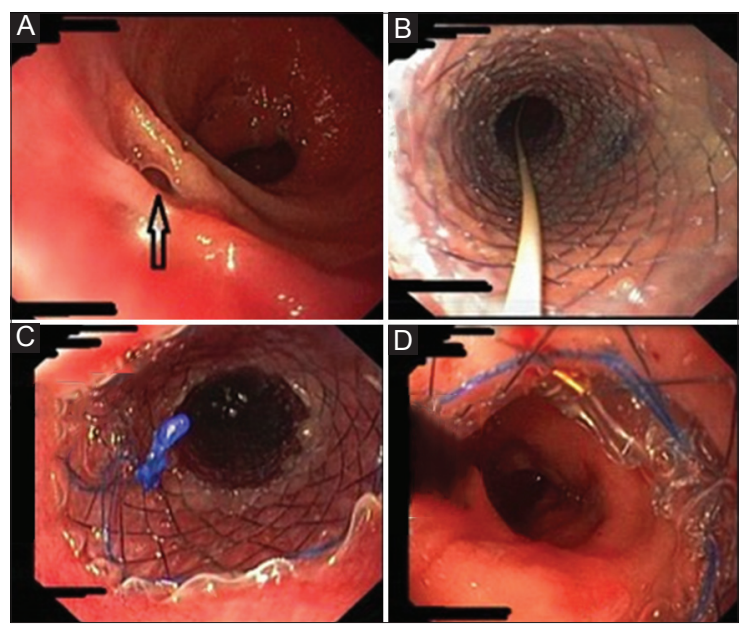

Figure 1 Use of a fully-covered self-expandable metallic stent (Hanarostent, M.I.Tech Co., Ltd., Seoul, Korea, length: $110 \mathrm{~mm}$, diameter: $70 \mathrm{~mm}$ ) to treat an anastomotic leakage following sleeve gastrectomy. (A) The arrow shows the anastomotic leak at the proximal aspect of the gastric sleeve; (B) Endoscopic image of the stent after full deployment; (C) Proximal aspect of the metallic stent into the lower esophagus proximal to the leak site; (D) Distal aspect of the metallic stent rested along the gastric antrum
It should be finally mentioned, that regarding patients in the early $(<4$ weeks) post-operative period with suspected leaks, major scientific associations recommend the use of the rapidly-absorved carbon dioxide for insufflation and the choice of water-soluble contrast radiography as the initial diagnostic method [6].

\section{Early postoperative hemorrhage}

Upper GI bleeding occurs in up to $4 \%$ of patients after RYGB; it occurs less commonly after LAGB, SG and VBG [3,20]. Early GI bleeding is typically presented within $48 \mathrm{~h}$ after surgery, most commonly originating from the staple line of gastric pouch or gastric remnant, and the GJ or jejunojejunal anastomosis.

Esophagogastroduodenoscopy performed in 27 of 30 postRYGB surgery early hemorrhage patients identified the bleeding site at the gastrojejunostomy staple line. Standard hemostatic techniques, such as heater probe cautery, epinephrine injection, and hemoclips were applied in 24 patients and bleeding control was achieved in all of them. Five re-bleeders required second endoscopic intervention; none required operation [26].

\section{Late complications}

In the late post-operative period numerous symptoms may arise warranting endoscopic evaluation. The most common among them are nausea/vomiting, gastroesophageal reflux, abdominal pain, diarrhea/malabsorption, and failure to lose weight or weight regain. In many cases, these are caused by surgery-associated anatomical alterations or by dietary/ behavioral factors. However, their persistence or inadequate relief with conservative measures should always prompt endoscopic evaluation. The most important late complications in operated bariatric patients, as well as their endoscopic diagnosis and treatment are presented below.

\section{Stenosis of the GJ anastomosis following RYGB}

RYGB can result in GJ anastomosis stenosis. Its incidence ranges from 2.9 to $23 \%$; the rate of postoperative strictures following open RYGB is $0.67 \%$ being lower in comparison with laparoscopic RYGB (4.63\%) [25,27-29]. Scanty data suggest that, similar to leaks, rates of stenosis can decrease by means of IOE $[23,24]$. Stoma stenosis diagnosis requires inability of a standard $9.5 \mathrm{~mm}$ diameter endoscope to pass through the anastomosis in patients presenting with dysphagia, vomiting and unhealthy rates of weight loss. GJ anastomotic stenosis can also present with worsening reflux symptoms that should always be endoscopically evaluated.

Treatment of anastomotic stenosis can be performed using Savary Gilliard bougies and through-the-scope (TTS) balloon dilations, the latter being the most commonly used technique with success rate exceeding $90 \%$. Symptoms resolution is the primary sign of successful treatment and it is usually attained at a stoma diameter of 10-12 $\mathrm{mm}$ [30], though reports of 
successful and uneventful dilations to 18 and $20 \mathrm{~mm}$ have been published [31].

Table 1 summarizes the results presented in a large systematic review regarding endoscopic dilatation in patients with stenosis after RYGB [32]. From 1988 to 2010, 23 studies -the majority of them conducted in the USA- with 760 patients who underwent RYGB (open or laparoscopic) were identified [30,31,33-53]. 1298 dilatations were performed using TTS balloons in 16 studies ( 2 of them used additionally Savary-Gillard bougies), while two studies did not report the dilation method and in three studies non-specified balloon types was used. Overall, the success rate of the procedures exceeded $90 \%$ (older series excluded), while complications occurred in less than $2 \%$ of the patients [32]. Moreover, in a large cohort of RYGB patients ( $\mathrm{n}=929)$, successful TTS balloon stricture dilation was related to the early -within 90 days after surgery- occurrence of the stricture since $98 \%$ and $61 \%$ of the early and late strictures were successfully treated [54].

Therefore, it can be concluded that TTS balloon dilation represents the primary means for postoperative anastomotic stenosis, while bougies dilation remains a complementary one. However, no head-to-head comparisons in terms of their safety and efficacy are available.

\section{Dilated GJ stoma with enlargement of the gastric pouch following RYGB}

A subset of patients regains weight long after RYGB; among other causes dilation of the GJ anastomosis also represents a possible factor that should always be endoscopically investigated. Endoscopic techniques used for GJ anastomotic tightening include sclerotherapy [55-59] and endoluminal suturing using the Endocinch suturing system (Bard Endoscopic Technologies, Billerica, MA, USA) [60-63], the Incisionless Operating Platform (USGI Medical Inc., San Clemente, CA, USA) [64-66], the StomaphyX system (Endogastric Solutions Inc., Redmond, WA, USA) [67-70], the OverStitch endoscopic suturing system (Apollo Endosurgery, Austin, TX, USA) [71,72], and, recently, serial argon plasma coagulation applications [73].

Table 1 Endoscopic treatment of anastomotic strictures in post-bariatric surgery patients (from reference 22, modified)

\begin{tabular}{|c|c|c|c|c|c|c|}
\hline Reference & Country & $\begin{array}{l}\text { Patients } \\
\text { no }\end{array}$ & $\begin{array}{l}\text { Dilatation } \\
\text { sessions }\end{array}$ & $\begin{array}{l}\text { Method of } \\
\text { dilatation }\end{array}$ & Complications & $\begin{array}{l}\text { Success } \\
\text { rate, } \%\end{array}$ \\
\hline Catalano et al 2007 [30] & USA & 26 & 63 & TTS & None & 100 \\
\hline Ahmad et al 2003 [31] & USA & 14 & 23 & TTS & None & 100 \\
\hline Ranjdeo et al 1989 [33] & USA & 8 & 11 & TTS & None & 100 \\
\hline Sanval et al 1992 [34] & USA & 20 & 23 & TTS & None & 100 \\
\hline Vance et al 2002 [35] & USA & 28 & 41 & NSB & None & 100 \\
\hline Barba et al 2003 [36] & USA & 24 & 33 & TTS & None & 100 \\
\hline Bel et al 2003 [37] & USA & 3 & 6 & SGB/TTS & None & 100 \\
\hline Nguyen et al 2003 [38] & USA & 29 & 35 & TTS & None & 100 \\
\hline Rossi et al 2004 [39] & USA & 38 & 61 & NM & 1 severe nausea/vomiting & 100 \\
\hline Escalona et al 2007 [40] & Chile & 53 & 71 & SGB & 1 pain & 100 \\
\hline Peifer et al 2007 [41] & USA & 43 & 56 & TTS & Minor bleedings & 98 \\
\hline Takata et al 2007 [42] & USA & 15 & 22 & TTS & None & 100 \\
\hline Caro et al 2008 [43] & Argentina & 111 & 200 & TTS & 2 perforations, 1 hematoma & 100 \\
\hline Ukleja et al 2008 [44] & USA & 61 & 128 & TTS & 3 perforations & 100 \\
\hline Schwartz et al 2004 [45] & USA & 30 & 68 & NSB & 4 perforations & 73 \\
\hline $\begin{array}{l}\text { Fernandez-Esparrach et al } \\
2008 \text { [46] }\end{array}$ & Spain & 24 & 38 & SGB & None & 100 \\
\hline Mishkin et al 1988 [47] & USA & 7 & 7 & NSB & None & 43 \\
\hline Costa et al 2009 [48] & Brazil & 30 & 48 & SGB/TTS & None & 100 \\
\hline Dolce et al 2009 [49] & USA & 11 & 11 & TTS & None & 91 \\
\hline Lee et al 2009 [50] & USA & 40 & 86 & TTS & None & 100 \\
\hline Mathew et al 2009 [51] & USA & 58 & 125 & $\mathrm{NM}$ & 4 perforations & 100 \\
\hline Ryskina et al 2010 [52] & USA & 58 & 117 & TTS & None & 100 \\
\hline Alasfar et al 2009 [53] & USA & 29 & 36 & TTS & None & 100 \\
\hline Yimcharoen et al 2012 [54] & USA & 72 & 2.3 per patient & TTS & 1 perforation related death & 85 \\
\hline
\end{tabular}

NSB, balloon type not specified; TTS, through-the-scope balloon; SGB, Savary-Gilliard bougie; NM, not mentioned 
The published data regarding the endoscopic management of post-RYGB anastomotic dilation are extracted from small case series and no long-term (more than one-year follow up) results are available (Table 2). Only Thompson et al, reporting the 12-month follow up of their initial Incisionless Operating Platform treatment of stoma dilation, showed that the results were durable with no long-term adverse events and that stoma repair to a diameter of less than $10 \mathrm{~mm}$ was related with greater sustainable weight loss [74].

It is noteworthy that nowadays the only commercially available device is the OverStitch Endoscopic Suturing System (Apollo Endosurgery, Austin, TX, USA) while the rest should be considered within clinical trials in reference centers. This system represents a cap-based device that adapts into a doublechannel endoscope allowing a curve needle to deploy sutures under direct visualization. There are only two small series on the management of RYGB failure. In the former series, nine patients with dilated gastrojejunostomy after RYGB underwent OverStitch system plication achieving weight loss ranging from 4.9 to $9.5 \mathrm{~kg}$ in one month. Emesis and bleeding were reported in one patient, while another one required balloon dilation due to liquids intolerance [74] In the latter series, OverStitch System treatment in eight patients with stoma dilation after
RYGB was associated with 6-8 kg weight loss in four of them, with no complications [72].

\section{Marginal ulcerations in RYGB}

Marginal ulcers appear in $20 \%$ of patients undergoing RYGB, more often during the first three months postoperatively. They commonly arise at the gastric side or the jejunal side of anastomosis. Many factors contribute to ulcer formation, such as bile acid reflux, ischemia, coexisting gastrogastric fistula, Helicobacter pylori infection, tension on the Roux limb, nonsteroidal anti-inflammatory drugs, nonabsorbable sutures, smoking and alcohol [75].

The patients with anastomotic ulcers usually present with persistent abdominal pain that indicates further endoscopic evaluation. Treatment includes proton pump inhibitors twice daily, tapered over 6 months. Eradication of Helicobacter pylori should be performed, if detected. Visible, non-absorbable sutures should be removed when possible to allow ulcer healing and treatment success should be evaluated with repeat endoscopy mainly in patients with persistent symptoms to rule out other complications $[3,76]$.

Table 2 Endoscopic treatment of dilated gastrojejunal stoma and enlargement of the gastric pouch following Roux-en-Y gastric bypass

\begin{tabular}{|c|c|c|c|c|c|}
\hline Reference & Country & $\begin{array}{c}\text { Patients } \\
\text { no }\end{array}$ & Method & Complications & Success rate, $\%$ \\
\hline Spaulding et al 2003 [55] & USA & 20 & Sclerotherapy & None & 100 \\
\hline Catalano et al 2007 [56] & USA & 28 & Sclerotherapy & None & 64 \\
\hline Spaulding et al 2007 [57] & USA & 32 & Sclerotherapy & None & 56 \\
\hline Giurgus et al 2014 [58] & USA & 48 & Sclerotherapy & None & 58 \\
\hline Abu Dayyeh et al 2012 [59] & USA & 231 & Sclerotherapy & $\begin{array}{l}15 \text { bleeding } \\
\text { (immediate/delayed) }\end{array}$ & 76 (at 12 months) \\
\hline Thompson et al 2006 [60] & USA & 8 & EndoCinch & None & 37 \\
\hline Thompson et al 2010 [61] & USA & 77 & EndoCinch & None & 96 \\
\hline Fernandez-Esparrach et al 2010 [63] & Spain & 6 & EndoCinch & 1 hematemesis & 83 \\
\hline Ryou et al 2009 [64] & USA & 5 & IOP & No & 100 \\
\hline Moullady et al 2009 [65] & USA & 20 & IOP & No & 85 \\
\hline Horgan et al 2010 [66] & USA & 116 & IOP & No & 97 \\
\hline Mikami et al 2010 [67] & USA & 39 & Stomaphy X & $\begin{array}{l}\text { Sore throat, epigastric pain } \\
\text { in most of the patients }\end{array}$ & 87 \\
\hline Leitman et al 2010 [69] & USA & 64 & Stomaphy X & None & 79 \\
\hline Manouchehri et al 2011 [70] & Canada & 14 & Stomaphy X & Headache, back pain & 100 \\
\hline Jirapinyo et al 2011 [71] & USA & 9 & OverStitch & 1 stenosis, 1 emesis & 100 \\
\hline Galvao Neto et al 2011 [72] & Brazil & 8 & OverStitch & 1 hematemesis & 50 \\
\hline Baretta et al 2015 [73] & Brazil & 30 & APC & 2 severe stenosis & $\begin{array}{c}\text { Decrease in mean } \\
\text { BMI and mean } \\
\text { diameter }(\mathrm{P}<0.05)\end{array}$ \\
\hline Thompson et al 2012 [74] & USA & 116 & ${ }^{*} \mathrm{IOP}$ & None & 97 \\
\hline
\end{tabular}




\section{Obscure Gl bleeding}

Investigation of iron deficiency anemia and obscure GI bleeding (OGIB) is challenging in surgically altered anatomy since potential bleeding sites such as the anastomotic site and the excluded stomach might not be accessible with conventional endoscopy. The American Society for Gastrointestinal Endoscopy recommendation for deep enteroscopy as the initial diagnostic evaluation in post bariatratric surgery patients with OGIB was based on experts' opinion [77]. Currently, there is only one case series focused on the efficacy of device assisted enteroscopy to successfully identify and treat lesions related to OGIB in the operated stomach [78]. More precisely, double balloon enteroscopy identified the responsible for OGIB lesion in 10 of the 12 patients with altered anatomy; in 9 of them the bleeding site was at the anastomosis and in one at the afferent limb. Endoscopic treatment was applied in eight patients, four patients required repeat endoscopy due to bleeding recurrence and there was one death attributed to perforation [78].

Finally, access to the excluded portion of the stomach and/or Roux limb can be facilitated through a surgically created gastrostomy, when traditional endoscopic techniques fail [6].

\section{Gastric band slippage and erosion}

Literature indicates that gastric band slippage rates vary from 2 to $14 \%[79,80]$. Patients commonly present with worsening epigastric pain, nausea/vomiting, acid reflux or even weight gain. The subsequent gastric prolapse is diagnosed with upper GI series and endoscopy and necessitates surgical intervention.

On the contrary, band erosion through the gastric wall develops in 0.2 to $33 \%$ of cases giving an overall incidence of $1.46 \%$ in a 2011 systematic review [81]. It occurs in a mean of 22.5 months after surgery [82] and its presentation involves pain, nausea, vomiting, hematemesis and failure to lose weight. Diagnosis is achieved by endoscopy which reveals the eroding part of the band into the lumen. Removal of the eroded band can be accomplished by either endoscopy (Fig. 2) or laparotomy. Several case reports/series have demonstrated feasibility, safety and efficacy of the endoscopic technique suggesting it as a first choice procedure in such cases [83-86].

\section{Endoscopic treatment of common bile duct stones}

RYGB is associated with long Roux limb and multiple luminal angulations, therefore poses several technical difficulties in accessing the biliary tree. Most available data come from series including patients that undergone RYGB for indications other than morbid obesity. ERCP in this population is performed with variable results by either enteroscopy (push, balloon-assisted, spiral) or by advancing the duodenoscope through a gastrostomy tract into the excluded stomach and duodenum.

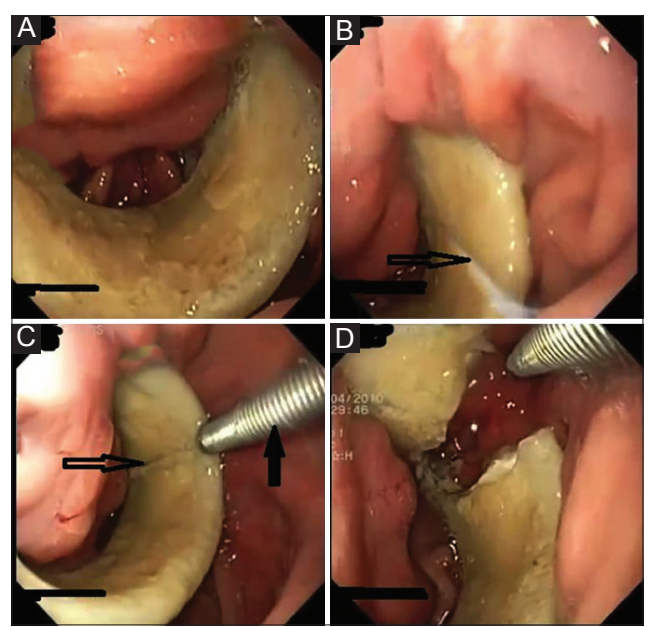

Figure 2 Endoscopic management of an eroded gastric band by means of a gastric band cutter. (A) More than $75 \%$ of the gastric band has migrated into the stomach; (B) The cutting wire of the device (shown by the open arrow) is positioned into the stomach through the working channel of the gastroscope next to the gastric band and thereafter folded around the band using a snare to retrieve it; (C) A metallic tube (cutter) shown by the solid arrow is inserted into the stomach over the folded cutting wire (open arrow) and it is pushed against the gastric band under direct endoscopic view; (D) The outer edge of the cutter is inserted into the tourniquet of the handgrip. By twisting the handle of the device the band is strangulated, cut and easily removed by gentle traction

A few studies including patients undergone RYGB for morbid obesity are available. Accordingly, Gostout et al reported for the first time the use of a pediatric colonoscope to treat common bile duct stones in operated bariatric patients [87]. Lopes et al reported that laparoscopy-assisted ERCP (LA-ERCP) in such patients was safe and facilitated biliary cannulation in $90 \%$ of them [88], while technical success was universal (100\%) in a recent study of similar design [89]. Moreover, "transgastrostomy" ERCP was successful in all patients after bariatric gastric bypass [90]. Two comparative studies in RYGB-treated obese patients have also come to light. Choi et al showed that ERCP via gastrostomy is more effective than double balloon enteroscopy ERCP in gaining access to the pancreatobiliary tree but it is hindered by the gastrostomy maturation delay and a higher morbidity [91]. On the other hand, LA-ERCP was found superior than balloon (either single- or double-) enteroscopy ERCP especially in patients with length of Roux limb plus biliopancreatic limb more than $150 \mathrm{~cm}$ [92]. Very recently, a novel method that overcomes the disadvantages of enteroscopy and laparoscopy has been proposed. In detail, endoscopic ultrasonography-facilitated access to the excluded stomach through the creation of a gastro-gastric fistula tract covered with a metallic stent that allowed the antegrade passage of a duodenoscope $[93,94]$. Furthermore, Law et al demonstrated a novel method to access the biliary tract with a duodenoscope that is advanced through a SEMS that was placed within an endoscopically-created gastrostomy tract [95]. Nevertheless, it should be noted that the optimal method to perform ERCP in RYGB patients remains 
unclear and the final choice should be based on endoscopist's expertise and available equipment.

\section{Concluding remarks}

Endoscopy is the method of choice to evaluate and even treat symptomatic bariatric surgery patients. The majority of the available data come from the USA and they derive from cohort and case series studies that enrolled relatively small numbers of patients. Therefore, there is still paucity of good quality randomized multinational, control studies. Currently numerous technical innovations are under strict clinical evaluation and hopefully, future advances in equipment and accessories will further facilitate endoscopic management of post-bariatric surgery complications and proper inspection of the anatomically altered upper GI tract.

\section{References}

1. Ng M, Fleming T, Robinson M, et al. Global, regional, and national prevalence of overweight and obesity in children and adults during 1980-2013: a systematic analysis for the Global Burden of Disease Study 2013. Lancet 2014;384:766-781.

2. Richdeep S G, Kevin A, Whitloc K, Rachid M. The role of upper gastrointestinal endoscopy in treating postoperative complications in bariatric surgery. J Interv Gastroenterol 2012;2:37-41.

3. Kumar N, Thomson CC. Endoscopic management of complications after gastrointestinal weight-loss surgery. Clin Gastroenterol Hepatol 2013;11:343-353.

4. Pollant S. The current status of bariatric surgery. Frontline Gastroenterol 2011;2:90-95.

5. Feitoza AB, Baron TH. Endoscopy and ERCP in the setting of previous upper GI tract surgery. Part I: reconstruction without alteration of the pancreatobilliary anatomy. Gastrointest Endosc 2001;54:743-749.

6. ASGE standards of practice committee, Evans JA, Muthusamy VR, et al. The role of endoscopy in the bariatric surgery patient. Gastrointest Endosc 2015;81:1063-1072.

7. Lee S, Carmody B, Wolfe L, et al. Effect of location and speed of diagnosis on anastomotic leak outcomes in 3828 gastric bypass cases. J Gastrointest Surg 2007;11:708-713.

8. Carucci LR, Turner MA, Conklin RC, DeMaria EJ, Kellum JM, Sugerman HJ. Roux-en-Y gastric bypass surgery for morbid obesity: evaluation of postoperative extraluminal leaks with upper gastrointestinal series. Radiology 2006;238:119-127.

9. Merrifield BF, Lautz D, Thompson CC. Endoscopic repair of gastric leaks after Roux-en-Y gastric bypass: a less invasive approach. Gastrointest Endosc 2006;63:710-714.

10. Eubanks S, Edwards AC, Fearing N, et al. Use of Endoscopic stents to treat anastomotic complications after bariatric surgery. J Am Coll Surg 2008;206:935-938.

11. Eisendrath P, Cremer M, Himpens J, Cadière GB, Le Moine $O$, Devière J. Endotherapy including temporary stenting of fistulas of the upper gastrointestinal tract after laparoscopic bariatric surgery. Endoscopy 2007;39:625-630.

12. Yimcharoen P, Heneghan HM, Tariq N, Brethauer SA, Kroh M, Chand B. Endoscopic stent management of leaks and anastomotic strictures after foregut surgery. Surg Obes Relat Dis 2011;7:628-636.

13. Puli SR, Spofford IS, Thompson CC. Use of self-expandable stents in the treatment of bariatric surgery leaks: a systematic review and meta-analysis. Gastrointest Endosc 2012;75:287-293.

14. El Mourad H, Himpens J, Verhofstadt J. Stent treatment for fistula after obesity surgery: results in 47 consecutive patients. Surg Endosc 2013;27:808-816.

15. Aurora AR, Khaitan L. Sleeve gastrectomy an the risk of leak: a systematic analysis of 4,888 cases. Surg Endosc 2012;26:1509-1515.

16. Arndtz K, Steed H, Hodson J, Manjunath S. The hidden endoscopic burden of sleeve gastrectomy and its comparison with Roux-En-Y gastric bypass. Ann Gastroenterol 2016;29:44-49.

17. Sakran N, Goitein D, Raziel A, et al. Gastric leaks after sleeve gastrectomy: a multicenter experience with 2,834 patients. Surg Endosc 2013;27:240-245.

18. Moon RC, Shah N, Teiheira AF, Jawad MA. Management of staple line leaks following sleeve gastrectomy. Surg Obes Relat Dis 2015; 11:54-59.

19. Vix M, Diana M, Marx L, et al. Management of staple line leaks after sleeve gastrectomy in a consecutive series of 378 patients. Surg Laparosc Endosc Percutan Tech.2015;25:89-93.

20. Martins BC, Retes FA, Medrado BF, de Lima MS, Pennacchi CM, Kawaguti FS, et al. Endoscopic management and prevention of migrated esophageal stents. World J Gastrointest Endosc 2014;6:49-54.

21. Murino A, Arvanitakis M, Le Moine O, Blero D, Deviere J, Eisendrath P. Effectiveness of endoscopic management using selfexpandable metal stents in a large cohort of patients with postbariatric leaks. Obes Surg 2015;25:1569-1576.

22. Seyfried F, Reimer S, Miras AD, et al. Successful treatment of a gastric leak after bariatric surgery using endoluminal vacuum therapy. Endoscopy 2013;45(Suppl 2) UCTN: E267-E268.

23. Hadad MA, Dehni N, Elamin D, Ibrahim M, Ghabra S, Nimeri A. Intraoperative endoscopy decreases postoperative complications in laparoscopic Roux-En-Y gastric bypass. Obes Surg 2015;25:1711-1715.

24. Haddad A, Tapazoglou N, Singh K, Averbach A. Role of intraoperative esophagogastroenteroscopy in minimizing gastrojejunostomy-related morbidity: experience with 2,311 laparoscopic gastric bypasses with linear stapler anastomosis. Obes Surg 2012;22:1928-1933.

25. Podnos YD, Jimenez JC, Wilson SE, Nguyen NT. Complications after lapaparoscopic gastric bypass. A review of 3464 cases. Arch Surg 2003;138:957-961.

26. Jamil LH, Krause KR, Chengelis DL, et al. Endoscopic management of early upper gastrointestinal hemorrhage following laparoscopic Roux-en-Y gastric bypass. Am J Gastroenterol 2008;103:86-91.

27. Goitein D, Papasavas PK, Gagné D, Ahmad S, Caushaj P. Gastrojejunal strictures following laparoscopic Roux-en-Y gastric bypass for morbid obesity. Surg Endosc 2005;19:628-632.

28. Gill RS, Whitlock AK, Mohamed R, Sarkhosh K, Birch WD, Karmali S. The role of upper gastrointestinal endoscopy in treating postoperative complications in bariatric surgery. J Interv Gastroenterol 2012;2:37-41.

29. Blackstone RP, Rivera LA. Predicting stricture in morbidly obese patients undergoing laparocopic Roux-en Y: a logistic regression analysis. J Gastrointestinal Surg 2007;11:403-409.

30. Catalano M, Chua T, Rudig G. Endoscopic balloon dilation of stomal stenosis following gastric bypass. Obes Surg 2007;17:298-303.

31. Ahmad J, Martin J, Ikramuddin S, Schauer P, Slivka A. Endoscopic balloon dilation of gastroenteric anastomotic stricture after laparoscopic gastric bypass. Endoscopy 2003;35:725-728.

32. Campos MS, Mello FS, Ferraz AAB, Brito JN, Nassif PN, GalvaoNeto Mdos P. Endoscopic dilatation of gastrojejunal anastomosis after gastric bypass. Arq Bras Cir Dig 2012;25:283-289.

33. Ranjdeo H, Bhuta K, Ackerman NB. Endoscopic management of gastric outlet obstruction following surgery for morbid obesity. Am Surg 1989;55:724-727. 
34. Sanyal AJ, Sugerman HJ, Kellum JM, Engle KM, Wolfe L. Stomal complications of gastric bypass: incidence and outcome of therapy. Am J Gastroenterol 1992;87:1165-1169.

35. Vance PL, Delange EE, Shaiffer B. Gastric outlet obstruction following surgery for morbid obesity: efficacy of fluoroscopy guided balloon dilatation. Radiology 2002;222:70-72.

36. Barba CA, Butensky MS, Lorenzo M, Newman R. Endoscopic dilation of gastroesophageal anastomosis stricture after gastric bypass. Surg Endosc 2003;17:416-420.

37. Bell RL, Reinhardt KE, Flowers JL. Surgeon performed endoscopic dilation of anastomotic strictures symptomatic gastrojejunal following laparoscopic Roux-en-Y gastric bypass. Obes Surg 2003;13:728-373.

38. Nguyen NT, Stevens CM, Wolfe BM. Incidence and outcome of anastomotic strictures after laparoscopic gastric bypass. J Gastrointest Surg 2003;7:997-1003.

39. Rossi TR, Dynda DI, Estes NC, Marshall JS. Stricture dilation after laparoscopic Roux-en-Y gastric bypass. Am J Surg 2005; 189:357-360

40. Escalona A, Devaud N, Boza C, et al. Gastrojejeunal anastomotic strictures alter Roux-en-Y gastric bypass: ampulatory management with the Savary-Gillard dilator. Surg Endosc 2007;21:765-768.

41. Peifer KJ, Shiels AJ, Azar R, Rivera RE, Eagon JC, Jonnalagadda S. Successful endoscopic management of gastrojejunal anastomotic strictures after Roux-en-Y gastric by-pass. Gastrointest Endosc 2007;66:248-252.

42. Takata MC, Clovica R, Cello JP, Posselt AM, Rogers SJ, Campos GM. Predictors, treatment, and outcomes of gastrojejunostomy stricture after gastric bypass for morbid obesity. Obes Surg 2007;17:878-884.

43. Caro L, Sanchez C, Rodriguez P, Bosch J. Endoscopic Balloon Dilation of Anastomotic Strictures after LRYGB. Dig Dis 2008;26:314-317.

44. Ukleja A, Afonso BB, Pimentel R, Szomstein S, Rosenthal R. Outcome of endoscopic balloon dilation of strictures after laparoscopic gastric bypass. Endosc Surg 2008;22:1746-1750.

45. Schwartz ML, Drew RL, Roiger RW, Ketover SR, Chazin-Caldie M. Stenosis of the Gastroenterostomy after Laparoscopic Gastric Bypass. Obes Surg 2004;14:484-491.

46. Fernandez-Esparrach G, Bordas JM, Llach J, et al. Endoscopic dilation with Savary-Gillard bougies of stomal strictures after gastric bypass laparoscopic in morbidity obese Patients. Obes Surg 2008;18:155-161.

47. Mishkin JD, Meranze SG, Burke DR, Stein EJ, McLean GK. Interventional radiologic treatment of complications following gastric bypass surgery for morbid obesity. Gastrointest Radiol 1988;13:9-14.

48. Costa AF, Almeida FF, Brado JL, Takahashi W. Endoscopic Treatment of Postoperative Complications Following Roux-en-Y Gastric Bypass (RYGB): Results of 73 cases. Gastrointest Endosc 2009;69:AB200-AB201

49. Dolce CJ, Dunnican WJ, Kushnir L, Bendana E, Ata A, Singh TP. Gastrojejunal Strictures alter Roux-en-Y Gastric Bypass With a 22MM Stapler. JSLJ 2009;13:306-311.

50. Lee JK, Van Dam J, Morton JM, Curet MJ, Banerjee S. Endoscopy is accurate, safe, and effective in the assessment and management of complications following gastric bypass. Gastrointest Radiol 1988;13:9-14.

51. Mathew A, Veliuona MA, DePalma FJ, Cooney RN. Gastrojejunal strictures after gastric bypass and efficacy of endoscopic intervention. Dig Dis Sci 2009;54:1971-1978.

52. Ryskina KL, Miller KM, Aisenberg J, Herron DM, Kini SU. Routine management of stricture after gastric bypass and predictors of subsequent weight loss. Surg Endosc 2010;24:554-560.

53. Alasfar F, Sabnis AA, Liu RC, Chand B. Stricture rate after laparoscopic Roux-en-Y Gastric bypass with a 21-mm circular stapler: the Cleveland Clinic experience. Med Princ Pract
2009;18:364-367.

54. Yimcharoen P, Henegham H, Chand B, et al. Successful management of gastrojejunal stricture after gastric bypass: Is timing important? Surg Obes Relat Dis 2012;8:151-157.

55. Spaulding L. Treatment of dilated gastrojejunostomy with sclerotherapy. Obes Surg 2003;13:254-257.

56. Catalano FM, Rudic G, Anderson JA, Chua TY. Weight regain after bariatric surgery as a result of a large gastric stoma: Endoterapy with sodium morrhuate may prevent the need for surgical revision. Gastrointest Endosc 2007;66:240-245.

57. Spaulding L, Osler T, Patlak J. Long-term results of sclerotherapy for dilated gastrojejunostomy after gastric bypass. Surg Obes Relat Dis 2007;3:623-626.

58. Giurgius M, Fearing N, Weir A, Micheas L, Ramaswamy A. Long-term follow-up evaluation of endoscopic sclerotherapy for dilated gastrojejunostomy after gastric bypass. Surg Endosc 2014;28:1454-1459.

59. Abu Dayyeh BK, Jirapinyo P, Weitzner Z, Barker C, et al. Endoscopic sclerotherapy for the treatment of weight regain after Rouxen-Y gastric bypass: outcomes, complications, and predictors of response in 575 procedures. Gastrointest Endosc 2012;76:275-282.

60. Thompson CC, Slattery J, Bundga EM, Lautz BD. Peroral endoscopic reduction of dilated gastrojejunal anastomosis after Roux-en-Y gastric bypass: a possible new option for patients with weight regain. Surg Endosc 2006;20:1744-1748.

61. Thompson CC, Roslin M, Chand B, et al. Restore: Randomized evaluation of endoscopic suturing transorally for anastomotic outlet reduction: a double-blind, sham-controlled, multicenter study for treatment of inadequate weight loss or weight regain following Roux-en-Y gastric bypass. Gastroenterology 2010;138:S-388.

62. Dakin GF, Eid G, Mikami D, Pryor A, Chand B. Endoluminal revision of gastric bypass for weight regain-a systematic review. Surg Obes Relat Dig 2013;9:335-342.

63. Fernandez-Esparrach G, Lautz DB, Thompson CC. Peroral endoscopic anastomotic reduction improves intractable dumping syndrome in Roux-en-Y gastric bypass patients. Surg Obes Relat Dis 2010;6:36-40.

64. Ryou M, Mullady DK, Lautz DB, Thompson CC. Pilot study evaluating technical feasibility and early outcomes of secondgeneration endo-surgical platform for treatment of weight regain after gastric bypass surgery. Surg Obes Relat Dis 2009;5:450-454.

65. Mullady DK, Lautz DB, Thompson CC. Treatment of weight regain after gastric bypass surgery when using a new endoscopic platform: initial experience and early outcomes (with video). Gastrointest Endosc 2009;70:440-444.

66. Horgan S, Jacobsen G, Weiss GD, et al. Incisionless revision of post-Roux-en-Y bypass stomal and pouch dilation: multicenter registry results. Surg Obes Relat Dis 2010;6:290-295.

67. Mikami DJ, Needleman B, Narula V, Durant J, Melvin WS. Natural orifice surgery: initial US experience utilizing the StomaphyX device to reduce gastric pouches after Roux-en-Y gastric bypass. Surg Endosc 2010;24:223-228.

68. Noria SF, Mikami DJ. Transoral surgery for morbid obesity. World J Gastrointest Endosc 2011;3:201-208.

69. Leitman IM, Virk CS, Avgerinos DV, et al. Early results of trans-oral endoscopic plication and revision of the gastric pouch and stoma following Roux-en-Y gastric bypass surgery. JSLS 2010;14:217-220.

70. Manouchehri N, Birch DW, Menzes C, Shi X, Karmali S. Natural orifice surgery: endoluminal pouch reduction following failed vertical banded gastroplasty. Obes Surg 2011;21:1787-1791.

71. Jirapinyo P, Abu Dayyeh B, Slattery J, et al. Endoscopic repair of dilated gastrojejunal anastomoses using a novel endoscopic suturing device. Gastroenterology 2011;140:S-118.

72. Galvao Neto M, Rodriguez L, Zundel N, Ayala JC, Campos J, Ramos A. Endoscopic revision of Roux-en-Y gastric bypass stomal dilation with a suturing device: preliminary results of a first out-of- 
United States series. Bariatric Times 2011;8:32-34.

73. Baretta GA, Alhinho HC, Matias JE, et al. Argon plasma coagulation of gastrojejunal anastomosis for weight regain after gastric bypass. Obes Surg 2015;25:72-79.

74. Thomson CC, Jacobsen GR, Schroder GL, Horgan S. Stoma size critical to 12-month outcomes in endoscopic suturing for gastric bypass repair. Surg Obes Relat Dis 2012;8:282-287.

75. Marano BJ Jr. Endoscopy after Roux-en-Y gastric bypass: a community hospital experience. Obes Surg 2005;15:342-345.

76. Frezza EE, Herbert H, Ford R, Watchtel MS. Endoscopic suture removal at gastrojejunal anastomosis after Roux en $\mathrm{Y}$ gastric bypass to prevent marginal ulceration. Surg Obes Relat Dis 2007;3:619-622.

77. ASGE Standards of Practice Committee, Fisher L, Lee Krinsky M, et al. The role of endoscopy in the management of obscure GI bleeding. Gastrointest Endosc 2010;72:471-479.

78. Skinner M, Peter S, Wilcox M, Mönkemüller K. Diagnostic and therapeutic utility of double-balloon enteroscopy for obscure GI bleeding in patients with surgically altered upper GI anatomy. Gastrointest Endosc 2014;80:181-186.

79. Ren CJ, Horgan S, Ponce J. US experience with the LAP-BAND system. Am J Surg 2002;184:46S-50S.

80. Rubenstein RB. Laparoscopic adjustable gastric banding at a U.S. center with up to 3-year follow-up. Obes Surg 2002;12:380.

81. Eqberts K, Brown WA, O’Brien P. Systematic review of erosion after laparoscopic adjustable gastric banding. Obes Surg 2011;21:1272-1279.

82. Suter M, Giusti V, Heraief E, Calmes JM. Band erosion after laparoscopic adjustable gastric banding: occurrence and results after conversion to Roux-en-Y gastric bypass. Obes Surg 2004;14:381-386.

83. Regusci L, Groebli Y, Meyer JL, Walder J, Margalith D, Schneider R. Gastroscopic removal of an adjustable gastric band after partial intragastric migration. Obes Surg 2003;13:281-284.

84. Neto MP, Ramos AC, Campos JM, et al. Endoscopic removal of eroded adjustable gastric band: lessons learned after 5 years and 78 cases. Surg Obes Relat Dis 2010;6:423-427.
85. Blero D, Eisendrath P, Vandermeeren A, et al. Endoscopic removal of dysfunctioning bands or rings after restrictive bariatric procedures. Gastrointest Endosc 2010;71:468-474.

86. Evans JA, Williams NN, Chan EP, Kochman ML. Endoscopic removal of eroded bands in vertical banded gastroplasty: a novel use of endoscopic scissors (with video). Gastrointest Endosc 2006;64:801-804.

87. Gostout CJ, Bender CE. Cholangiopancreatography, sphincterotomy, and common duct stone removal via Roux-en-Y limb enteroscopy. Gastroenterology 1988;95:156-163.

88. Lopez TL, Clements RH, Wilcox CM. Laparoscopy-assisted ERCP: experience of a high-volume bariatric surgery center (with videos). Gastrointest Endosc 2009;70:1254-1259.

89. Falcão $M$, Campos JM, Galvão Neto $M$, et al. Transgastric endoscopic retrograde cholangiopancreatography for the management of biliary tract disease after Roux-en-Y gastric bypass treatment for obesity. Obes Surg 2012;22:872-876.

90. Martinez J, Guerrero L, Byers P, et al. Endoscopic retrograde cholangiopancreatography and gastroduodenoscopy after Rouxen-Y gastric bypass. Surg Endosc 2006;20:1548-1550.

91. Choi EK, Chiorean MV, Coté GA, et al. ERCP via gastrostomy vs. double balloon enteroscopy in patients with prior bariatric Rouxen-Y gastric bypass surgery. Surg Endosc 2013;27:2894-2899.

92. Schreiner MA, Chang L, Gluck M, et al. Laparoscopy-assisted versus balloon enteroscopy-assisted ERCP in bariatric post-Rouxen-Y gastric bypass patients. Gastrointest Endosc 2012;75:748-756.

93. Kedia P, Sharaiha RZ, Kumta NA, Kahaleh M. Internal EUS-directed transgastric ERCP (EDGE): game over. Gastroenterology 2014;147:566-568.

94. Kedia P, Kumta NA, Sharaiha R, Kahaleh M. Bypassing the bypass: EUS-directed transgastric ERCP for Roux-en-Y anatomy. Gastrointest Endosc 2015;81:223-224.

95. Law R, Wong Kee Song LM, Petersen BT, Baron TH. Single-session ERCP in patients with previous Roux-en-Y gastric bypass using percutaneous-assisted transprosthetic endoscopic therapy: a case series. Endoscopy. 2013;45:671-675. 